Article

\title{
Hate in a Tweet: Exploring Internet-Based Islamophobic Discourses
}

\author{
Giulia Evolvi (D) \\ Center for Religious Studies (CERES), Ruhr University Bochum, Universitätsstr. 90a, 44789 Bochum, Germany; \\ giulia.evolvi@rub.de
}

Received: 1 August 2018; Accepted: 6 October 2018; Published: 10 October 2018

check for updates

\begin{abstract}
Islamophobia is the unfounded hostility against Muslims. While anti-Muslim feelings have been explored from many perspectives and in different settings, Internet-based Islamophobia remains under-researched. What are the characteristics of online Islamophobia? What are the differences (if any) between online and offline anti-Muslim narratives? This article seeks to answer these questions through a qualitative analysis of tweets written in the aftermath of the 2016 British referendum on European Union membership (also known as "Brexit"), which was followed by a surge of Islamophobic episodes. The analysis of the tweets suggests that online Islamophobia largely enhances offline anti-Islam discourses, involving narratives that frame Muslims as violent, backward, and unable to adapt to Western values. Islamophobic tweets also have some peculiar characteristics: they foster global networks, contain messages written by so-called "trolls" and "bots," and contribute to the spreading of "fake news." The article suggests that, in order to counteract online Islamophobia, it is important to take into account the networked connections among social media, news media platforms, and offline spaces.
\end{abstract}

Keywords: Islamophobia; internet; Twitter; Brexit; Islam; Muslims; UK; digital media

\section{Introduction}

The Internet can amplify ideas and opinions of groups and individuals. This means that hate speech may also find a fertile ground on certain websites and social network platforms. Far-right and racist European movements, such as Britain First in the UK and Pegida (Patriotic Europeans against the Islamization of the West) in Germany, often employ digital spaces as the preferred venue to circulate their messages and recruit new members (Wood and Finlay 2008; Allen 2014). They spread Internet-based racism and often contribute to diffuse an image of Islam as incompatible with Western values. This may result in physical actions against Muslims (Ekman 2015). A study conducted by the British association Tell Mama (Awan and Zempi 2015), whose aim is to counter anti-Muslim crimes, finds that victims of Islamophobia usually experience indeed both online and offline harassment.

Many instances of online Islamophobia can be traced on Twitter. According to Tell Mama, for example, a trending hashtag in 2015 was the disturbing \#KillAllMuslims. In the same year, some Islamophobic actors employed the hashtag \#Pakemon (a portmanteau of "Pakistan" and the name of the game "Pokemon") to kindle an offline anti-Muslim campaign (Tell Mama 2016a). The creation of anti-Muslim hashtags tend to be connected to specific events that trigger Islamophobic attacks: for instance, many employed Twitter to blame Muslims for the ISIS-claimed 2015 attacks in Paris (Magdy et al. 2015). Sexual assaults in Cologne on New Year's Eve 2015/2016 led to the creation of the hashtags "rapefugee," "rapeugee," and "rapugee," portmanteaus of "rape" and "refugee" often used to connect Islam with sexual violence (Würschinger et al. 2016).

The spread of Islamophobic discourses on social networks such as Twitter compels scholars to pay equal attention to offline aggression and online Islamophobia. Arguably, hate speech and Islamophobia 
have similar characteristics and comparable impacts in both online and offline settings (Awan and Zempi 2015). However, according to Brown (2018), online hate speech differs from offline abuses because the Internet is characterized by anonymity, lack of physical presence, relatively cheap and easy access, and, in particular, instantaneousness (p. 10). While an academic focus on online Islamophobia would help to better assess its characteristics and its relation with offline attacks, it largely remains under-researched (Awan 2014, p. 137). This lack of attention for Internet-based Islamophobic discourses may also have practical consequences, as the definition of hate speech on social networks is often a gray area, changes from country to country, and is seldom punished. Therefore, this article explores Islamophobia on Twitter starting from the following questions: What are the characteristics of online Islamophobia? What are the differences (if any) between online and offline anti-Muslim narratives?

This article will, first, offer a definition of Islamophobia and its implications, quoting the report produced by the Runnymede Trust (1997). I will proceed by contextualizing Islamophobia in relation to the case study of anti-Muslim tweets sent in the aftermath of the EU referendum in the UK. I will then describe the main characteristics of these Islamophobic tweets, analyzing them in relation to the eight views of Islam described by the Runnymede Trust. My argument is that the peculiarities of post-Brexit Twitter Islamophobia include the creation of global networks between far-right actors, messages written by trolls and bots, and the spreading of fake news. In conclusion, I will discuss how online Islamophobia enhances offline discourses and actions, while at the same time creating networks of actors between media and non-media venues.

\section{Islamophobia: Definitions and Implications}

Islamophobia-formed by the word "Islam" with the suffix "-phobia"-literally means "fear of Islam." This suggests a view of Islam as "other" to and threatening for Western culture. Islamophobia can be traced back to 7th Century Europe and is often the result of an "Orientalist" vision of the Arab world (Said 1979). Recently, the term began to be closely connected to the so-called "war on terror," because terrorist attacks, starting from $9 / 11$, had a negative impact on the social perception of Islam (Bakali 2016). This is reinforced by negative media representations of Islam (Poole and Richardson 2006). While it is far from being a new form of bigotry, Islamophobia can have different nuances depending on socio-political contexts: Beydoun (2018), for example, explains that American Islamophobia is influenced by European events such as Brexit, but at the same time is connected to the national legal and political system, and the racial and religious demographics of the US. Whilst there is no universal understanding of the term Islamophobia, this article mainly refers to the definition provided by the Runnymede Trust.

The Runnymede Trust (1997) defines Islamophobia as "unfounded hostility towards Islam" and explains that "it refers also to the practical consequences of such hostility in unfair discrimination against Muslim individuals and communities, and to the exclusion of Muslims from mainstream political and social affairs" (p. 4). In order to distinguish between Islamophobia and legitimate criticism, the Runnymede Trust presents eight open and closed views of Islam. Open views lead to constructive and founded criticism of Muslim practices and beliefs, and they produce debates that are acceptable in a democratic society. On the contrary, closed views are based on prejudices and hostility. For example, a closed view would consider Islam as monolithic and unable to change, while its open counterpart would acknowledge the inner diversity within Islam. The report presents eight closed views that constitute the basis of Islamophobia (p. 5):

1. Monolithic: Islam is seen as a monolithic entity that does not change in encountering new realities

2. Separate: Islam is considered as separate from and having nothing in common with other cultures

3. Inferior: Islam is deemed as inferior to the West, irrational, barbaric, primitive, and sexist

4. Enemy: Islam is portrayed as violent, aggressive, threatening, and engaging in a "clash of civilization"

5. Manipulative: Islam is considered as a political ideology, not a sincere religious belief 
6. Criticism of the West rejected: Muslim criticism of the West are rejected out of hand

7. Discrimination defended: Discriminatory practices against Muslims are justified and Muslims are excluded from mainstream society

8. Islamophobia seen as natural: Islamophobia is accepted as something natural and normal.

These eight views are symptomatic of Islamophobia because they do not lead to conversations with Muslims and debates about Islam, as open views would do, but rather aim only at diminishing and aggressing Muslims. The views are indicators of Islamophobia and they can often be combined together. Indeed, while the Runnymede Trust presents them as separate items for the sake of clarity, they actually "are joined together in vicious circles, each making the other worse" (Runnymede Trust 1997 , p. 4). Keeping in mind how the eight views can be entangled with each other, the Runnymede Trust report can be useful in defining and recognizing forms of Islamophobia, as showed by the numerous academic works that mention it (Gardner et al. 2008; Hopkins and Kahani-Hopkins 2006; Hussain and Bagguley 2012; Hussain and Sherif 2014).

Closed views of Islam can result in physical as well as verbal and symbolic violence. Practical examples of Islamophobia include harassing Muslims because of their religious garments and appearance, with cases of physical aggression and veils ripped; anti-Muslim discrimination in public places, such as schools and hospitals; acts of violence against Muslim religious spaces, for example pig heads left in front of mosques. Because Islamophobia tends to be triggered by visible Muslim identities, it has a strongly gendered dimension when it involves aggression against headscarf-wearing Muslim women (Allen 2015).

In describing instances of Islamophobic actions and discourses, Mondon and Winter (2017) distinguish between "illiberal" and "liberal" Islamophobia. The former, expressed for example by the claims of right-wing xenophobic parties such as the Italian Lega Nord, the British UKIP, the French Front National, is an open and manifest form of Islamophobia. Illiberal Islamophobia targets all Muslims only because of their religious belonging, and is generally criticized in mainstream media and social discourses. Liberal Islamophobia, on the contrary, is anchored in a progressive narrative and only focuses on religious and cultural values. For example, it opposes the female veil in the name of Western gender norms and women's rights, and defends anti-Islam discourses to protect freedom of speech. This type of Islamophobia is subtler as it distinguishes between "good" Muslims, able to accept Western norms, and "bad" Muslims, who supposedly live accordingly to different norms.

In the 20th-anniversary report, the Runnymede Trust (Elahi and Khan 2017) updates the definition of Islamophobia by insisting on its complex and multi-faced character, and focusing on its practical consequences and the socio-political exclusion of Muslims. In so doing, the report discusses Islamophobia as a form of cultural racism. Islamophobia works, indeed, on the assumption that cultural differences are insurmountable, and it is often connected to xenophobia. This form of racism involves attacks that are not triggered by skin color only, but also by visible and manifest belonging to Islam (Garner and Selod 2015). According to Grosfoguel (2017), cultural racism emerged prominently in the last 60 years, but it needs to be understood in relation to the long history of "othering" of non-European, non-White, and non-Christian subjects. Therefore, it would be limiting to frame Islamophobia only as a religious issue, when it regards society and politics at large (Esposito and Kalin 2011).

Considering Islamophobia as a form of cultural racism elicits parallelisms with other types of discrimination, in particular anti-Semitism. Indeed, both Jews and Muslims have been considered as "other" to Europe because of their cultural belongings (Meer and Noorani 2008). According to Linehan (2012), for example, Islamophobia in the UK is similar to British anti-Semitism between the two wars because it entails conspiratorial, cultural, and religious forms of discrimination: it is based on the idea that Muslims seek to destroy the West, that they are culturally incompatible with Western values, and that their religious practices are "barbaric" if compared to those of Christianity. These elements can also be traced in anti-Semitic discourses.

Islamophobia, therefore, is a nuanced concept that refers to unfunded hostility against Muslim individuals in virtue of their belonging to Islam, is entangled with other social elements, and can 
be considered as a form of cultural racism. Zempi and Awan (2016) explore Islamophobia in online settings. Internet-based Islamophobia exists in a context where perpetrators find a digital safe space to target people because of their perceived differences. According to Zempi and Awan,

Online Islamophobia can be defined as Islamophobic prejudice that targets a victim in order to provoke, cause hostility and promote intolerance by means of harassment, stalking, abuse, incitement, threatening behavior, bullying and intimidating of the person or persons, via all platforms of social media. (p. 6)

This broad definition of online Islamophobia includes a variety of different actions. However, it remains unclear what the specific characteristics of Internet-based Islamophobia are and whether (and how) it can be distinguished from offline anti-Muslim aggression. This article reflects on the implications of online Islamophobia through a case study: the analysis of anti-Muslim tweets sent in the aftermath of the British referendum.

\section{Brexit and Twitter Islamophobia}

The British referendum on European Union (EU) Membership, commonly referred to as "Brexit," happened on the 23 June 2016. Citizens were called to choose between the "Remain" position, if they wished the UK to continue being part of the European Union, and the "Leave" position, if they preferred it to exit the EU. After a long campaign, the referendum sanctioned the victory of the Leave position with $51.9 \%$ of votes.

Brexit is a compelling case study of online Islamophobia for two main reasons. First, the referendum was often framed in terms of racial and religious belonging, because some supporters of the Leave position advocated for the preservation of British culture. While the choice of leaving the EU would prevent circulation of European citizens from predominantly white and Christian countries, many narratives centered on the need of stopping an alleged "Muslim invasion" that would threat UK identity. These arguments were often combined with anxieties that Turkey, a predominantly Muslim country, would join the EU and benefit from free movement of citizens. With regard to these anxieties, British politician and Leave supporter Nigel Farage unveiled a poster that shows a queue of migrants, mostly men and brown-skinned (Figure 1). The poster, which has been criticized for inciting racial hatred, says "Breaking Point: the EU has failed us all" and "We must break free of the EU and take back control" (Stewart and Mason 2016). This episode shows how racism has been a key factor during the Brexit campaign because EU membership was (misleadingly) put in connection with a growing migrant population. Racist feelings during the campaign likely caused the spike of hate crimes in the week after the referendum, with the association Tell Mama (2016b) reporting a substantial rise in Islamophobic attacks.

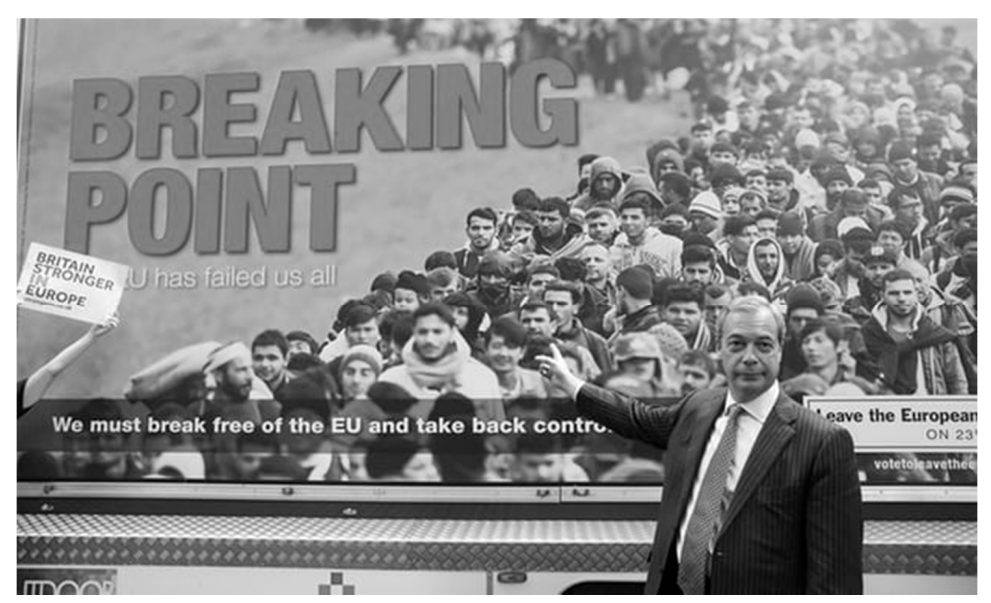

Figure 1. British politician Nigel Farage unveiling a racist poster during the Brexit campaign. (Stewart and Mason 2016). 
The second reason is that media, and especially digital media, decisively helped to diffuse the ideas of the Leave position. On social networks, the Leave campaign was more successful than its counterpart in spreading powerful and emotional messages and attracting users' participation (Jackson et al. 2016). In particular, the Leave campaign gained considerable attention on Twitter, a platform used to talk about Brexit in relation to immigration, economy, and security. These topics were often spread through Islamophobic hashtags and keywords such as \#IslamIsTheProblem and "Muslim terrorists." (Miller et al. 2016). Therefore, the Internet arguably helped Leave supporters to spread their ideas, and it is not surprising that this includes a number of anti-Muslim tweets.

In an earlier study, I explored post-Brexit Islamophobia to reflect on Twitter and group polarization (Evolvi 2017). My results suggest that Twitter facilitates the creation of opinion-based groups that reinforce existing beliefs and that are based on complex understandings of national identities, which involve ethnicity, political belonging, and gender. Islamophobic groups on Twitter rarely enter in online conversation with Muslims, but rather establish an antagonistic relationship with them and blame Islam as a scapegoat for social problems. What still remains to be explored are the intrinsic characteristics of this type of online Islamophobia and its connections with anti-Muslim attacks in offline settings. This article employs the same dataset of the previous study to discuss the peculiarities of anti-Islam narratives in online venues, with a focus on Twitter.

\section{Studying Twitter: Methods}

Studying Twitter can help to better understand how people express their ideas in relation to certain events because it is a public, free, and user-generated platform (Conover et al. 2012). Users can write their tweets in 280 characters (140 at the time the tweets analyzed in this article were written), embed images and links, quote other users (via "@username"), and circulate tweets written by others on their profiles (a practice called "re-tweeting"). They can also embed hashtags, which are words that people emphasize through the symbol "\#". By clicking on a hashtag, it is possible to find tweets that employ the same word, and therefore to enter in conversation with other users who are tweeting about the same topic. Hashtags become "trending" when they reach a particular visibility because users frequently write and re-tweet them in a given timeframe (Wilkinson and Thelwall 2012). This research focuses on the hashtag \#Brexit in relation to the keywords "Muslim" and "Islam." \#Brexit became a trending topic immediately after the decision to withdraw from the EU and it is the most frequently used hashtag in relation to the referendum, being employed both by Leave and Remain supporters (Howard and Kollanyi 2016).

In order to collect relevant tweets, I did an exploratory virtual observation of Twitter narratives immediately after the British referendum. Because the days in the aftermath of the referendum registered, understandably, the higher number of reactions, I focus on tweets from the 23 to 30 June 2016. I collected tweets that were written in English, but because I did not place any geographical restriction, their authors were based in various parts of the world. This choice was motivated by the global character of certain anti-Islam discourses. While the British referendum mainly regards the UK, its symbolic impact extends to a number of Western countries, especially for what concerns issues of migration and free circulation of people. Indeed, as will be analyzed in the following sections, many tweets in the dataset are based in and refer to countries other than the UK. Some of them celebrate Brexit as an anti-immigration vote that could influence other political decisions, such as presidential elections in the US. Therefore, analyzing tweets from a variety of geographical areas allows for a broader understanding of the political ideologies that might legitimate Islamophobic discourses and actions worldwide.

I collected 2005 tweets that, in this timeframe, were labeled as "popular" by the Twitter search API. The API, short for "Application Program Interface," is the platform that provides access to public Twitter data. These tweets are not all Islamophobic, as some show support and empathy for Muslims and Islam, and others are neutral in character. In order to distinguish between Islamophobic and non-Islamophobic tweets, I performed a sentiment analysis (Philander and Zhong 2016), manually 
coding tweets into sentiment categories based on their attitude towards Islam. I classified as "Islamophobic" all tweets that employ abusive language against Muslim migrants, refugees, or citizens, and that consider Islam as "other" to European and British culture. In case of uncertainty, the analysis took into account also the author's Twitter biography and their previous tweets and retweets to better understand their context of narrative production. By so doing, I was able to individuate 1329 tweets that express Islamophobic views and analyze them in this article.

The relatively small dataset allows for an in-depth qualitative analysis and a manual coding of recurring narratives. Because the analyzed tweets only include 140 characters and often employ slang and abbreviations, a machine-based analysis might fail to detect some of their nuances. In addition, a human coder can better analyze emotional language, irony or sarcasm, often found in the dataset. I captured narrative nuances by looking at text, and, when present, images, links to other web pages, users' biographies, and re-tweets. I individuated the most-frequently used words in tweets in order to define dominant discursive patterns (Figure 2). This qualitative methodological approach helps to gain an idea of how aggression against Muslims is reproduced on Twitter. I will, first, analyze the tweets in the dataset in relation to the aforementioned definition of Islamophobia provided by the Runnymede Trust. Second, I will discuss the peculiar characteristics of online Islamophobia.

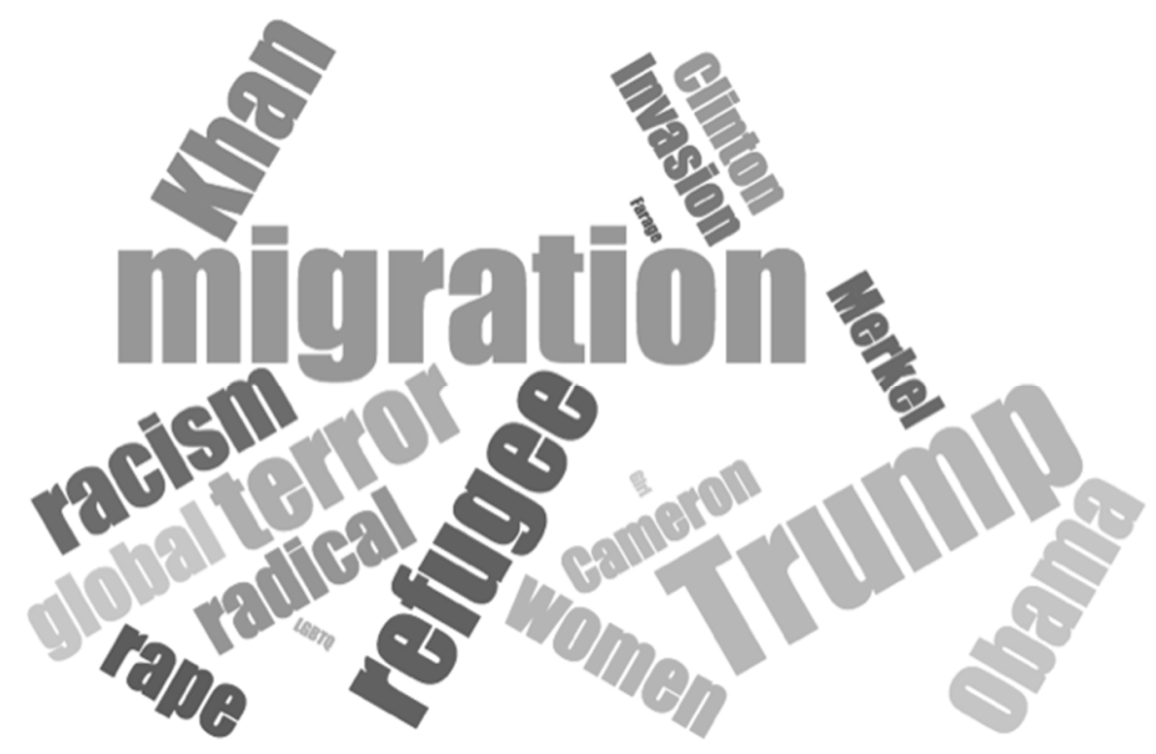

Figure 2. Most-frequently used terms in the dataset of tweets.

\section{Analysis of Islamophobic Tweets}

Twitter is a public platform that allows to create general statements and to directly respond to other users. Therefore, Islamophobic users can target a Muslim person or talk about Islam in general. In the case of the sample collected in relation to the Brexit referendum, the majority of tweets belong to the second category. Sometimes they re-tweet a text written by a self-identified Muslim, but messages tend to make broad anti-Islam statements rather than directly belittling an individual. The majority of these tweets represent what Mondon and Winter (2017) define as "illiberal Islamophobia": a type of anti-Muslim verbal violence that openly targets people only by virtue of their belonging to Islam. Therefore, these tweets do not criticize the opinion of a Muslim individual or group, but express hate against Islam in its whole.

Anti-Islam statements are often paired with references to ethnicity, gender, and politics. Figure 2 represents a word cloud of the terms that are most frequently used in the tweets, excluding those that are not relevant for the analysis (such as prepositions and conjunctions). Each term indicates a semantic area, for example "migration" includes references to migrants and immigrants, too. As the figure shows, many tweets—combined, $21 \%$ of the dataset—refer to migration or refugees, which are usually negatively talked about as causes for the growth of Islam. There are also frequent mentions to 
politicians, found in 31\% of the dataset: the majority of these tweets talk about Donald Trump, but there are also references to Muslim London mayor Sadiq Khan, then US president and presidential candidate Barack Obama and Hillary Clinton, and German chancellor Angela Merkel. These references show that the tweets discuss politics globally, often identifying left-wing politicians as Muslim allies, and praising right-wing politics for being anti-Islam. Islamophobic discourses in the tweets are further enhanced by numerous mentions of terrorism, radicalism and rape, generally used to connote Islam as violent and backward. In so doing, many tweets perpetuate closed views against Islam, as in the Runnymede Trust's definition (Runnymede Trust 1997).

\subsection{Internet-Based Views of Islam}

The aforementioned definition of Islamophobia elaborated by the Runnymede Trust includes eight views of Islam. While the definition does not mention the Internet and was written before the creation of Twitter, these eight views can be found also in the analyzed sample of post-Brexit tweets. I here provide examples of tweets in relation to each of the eight views as a starting point to show some of the predominant themes and broad patterns in the dataset. This way of presenting data follows the structure of the Runnymede Trust report, which considers the views in turn and provides examples for each of them. However, it is important to keep in mind that the views often overlap: as previously mentioned, they are not meant to be used individually, but rather they feed off each other. The analysis reveals indeed that most of the tweets could be considered as expressing several of the views, if not all eight.

The first view is that Islam is monolithic, and therefore unable to change or adapt to new contexts. This view is often expressed in the Islamophobic tweets analyzed in this article, because they tend to picture Islam as a totalizing religion and to use the term "radical" to describe it, as shown in Figure 2. A tweet, for example, says "Death penalty for apostasy, adultery, homosexuality ... is not radical ... it's Islam! \#Brexit." (25 June 2016). The tweet claims that Islam needs to be rejected because it necessarily holds an intrinsic violent character, being unable to accept certain behaviors. This view implies that Muslims should be banned—arguably, through Brexit-because there is no such thing as a "non-radical Islam." It refuses to acknowledge the inner heterogeneity of Islam, and starts from the (false) premises that no Muslim would ever accept "apostasy, adultery, homosexuality" because of the unchangeable character of their beliefs.

Islam is also considered as being separate from other cultures. According to this view, which echoes the idea that Islam is monolithic and unable to adapt to different contexts, Muslims do not share anything in common with non-Muslims. A tweet says in this respect "Secular democracy is not a suicide pact. Islam is simply incompatible with Western civilization. Bravo for \#Brexit" (25 June 2016). This tweet, as many others do, implies that Brexit is a necessary measure to stop a Muslim "invasion" (which would lead to "suicide") because of the incompatibility between Islam and the West. Therefore, European Muslims are framed in negative terms only, and no attention is given to their personal stories, ideas, and behaviors. The possibility of Muslims living in the UK in a peaceful way and adapting to European culture is not considered.

The alleged incompatibility between Muslims and European values is justified by a view of Islam as being inferior to the West. For instance, Muslims are deemed unable to respect gender equality, as shown by the references to rape and women (Figure 2). Often, tweets perpetuate these discourses by invoking the need for protecting Western women from Muslims, framed as following "primitive" and irrational sexual impulses. An example of this view can be found in the tweet "In the EU I see bombs in France \& Brussels then Muslim refugees attacking women on German Streets \#Brexit" (23 June 2016). The tweet employs terrorist attacks (with references to bombings occurred in France and Belgium in 2015 and 2016) and episodes of sexual harassment (mentioning the happenings in Cologne on New Year's Eve 2015/2016) as proof of the "barbaric" character of Muslims. By implying that Muslims always behave in a backward and violent way, the tweet claims that Brexit would protect the UK against Muslim-led actions that supposedly happen only in continental Europe. 
Because of its alleged inferiority, Islam is portrayed as being an enemy of the West. This view stresses the supposedly violent character of Muslims, who are often seen as engaged in a "clash of civilization" against the Western world and propagating terrorism, as can be seen from Figure 2. From this perspective, Brexit is a strategy to prevent an open conflict between Muslims and non-Muslims in the UK. For example, a tweet says "By the looks of it \#brexit is a vote against Islamic immigration to UK. Will the west go to war with islam in the near future?" (24 June 2016). The tweet suggests that there is the possibility of a conflict between Islam and the West. While it is not clear what the circumstances of this presumed "war" are, this type of Twitter narrative further reinforces the idea that Islam can never be part of British and European culture.

In the context of the Brexit debate, Islam is often seen as a political ideology rather than a religion. Its manipulative character is allegedly found in a global conspiracy that seeks to foster the growth of Islam. As previously mentioned, many tweets blame politicians such as then US President Barak Obama and German Chancellor Angela Merkel for pushing the secret agenda of helping Muslims to "invade" Europe and the West in general. This "conspiracy" is often deemed "globalist agenda," as shown by a tweet: "The expansion of \#Islam in the West is critical to \#EU globalist agenda! Citizens of the \#UK wised up to this scheme \#Brexit" (26 June 2016). From this perspective, people voted to leave the EU because they understood that there is a "conspiracy" behind the growth of Islam, described as a manipulative ideology supported by global political elites. It is for this reason that, as shown in Figure 2, one of the most frequently used words in the analyzed tweets is "global."

Many of these Islamophobic narratives also rejects Muslim criticism of the West. Muslims are not granted agency to articulate and diffuse their own opinions, especially when they include any form of criticism against non-Muslims. In the case of Brexit, Muslims are often blamed for supporting the Remain position. "The fact that Islam is so mad about \#brexit should be an eye opener to Brits on how bad you stumped their invasion" (24 June 2016): this tweet frames Muslims' vote to remain in the EU not as a genuine political ideology, but rather as part of a general hostility against the West. This type of tweet sometimes targets self-identified Muslim individuals for expressing pro-EU opinions, often re-tweeting Muslim users with Islamophobic comments.

In expressing Islamophobic statements, many tweets also defend discrimination. The exclusion of Muslims from mainstream society is indeed seen as a necessary precaution against Islam, and seldom recognized as being problematic. This view is expressed by the tweet "Islam isn't a race. Who cares about their feelings? They are invading foreigners \#DeportAllMuslims \#Brexit" (24 June 2016). This tweet, which clearly displays an illiberal type of Islamophobia, dehumanizes Muslims and claims that they should all be deported because of their religion. Muslims are often considered "other" to the West and confused with migrants (as shown in Figure 2) in a way that conflates religion and race. However, the tweet justifies anti-Muslim measures on the basis that Islam is a religion-and, therefore, something people willingly embrace-rather than a race. This distinction permits Islamophobic users to provide a justification for the harassment of Muslims while claiming not to be "racists."

The distinction between Islamophobia and racism often provides justifications to see Islamophobia as natural. While racism is negatively framed because people cannot choose their race, Islamophobia is justified as it targets religious belonging. This perspective refuses to acknowledge Islamophobia as a form of cultural racism, as previously discussed. For example, a tweet claims "It's not 'racist' to desire to protect your country and culture from Muslim takeover \& destruction ... Islam is NOT a race. \#Brexit" (27 June 2016). The tweet justifies the perpetuation of anti-Islam narratives because of the alleged choice that Muslims make in being violent. It does not only stress the incompatibility of Islam and the West, but it also normalizes Islamophobia by distinguishing it from racism, which is also a term that frequently appears in the dataset (Figure 2). From this perspective, Muslims supposedly invite Islamophobia because of their unwillingness to accept Western norms. Once again, these tweets dehumanize Muslims and perpetuate Islamophobia by failing to recognize different facets of Islam.

By looking at the Runnymede Trust's eight views of Islam, it is possible to see how Internet-based Islamophobia is largely an enhancement of discourses that already exist in offline spaces. While the 
eight views are by no means exhaustive and need to be considered as entangled with each other, they are useful to provide some examples of anti-Islam narratives produced on Twitter. By analyzing them in relation to the context of production of the tweets-the rise of xenophobic and Islamophobic discourses in the aftermath of the British Referendum-it is possible to consider them not only as simple indicators of Islamophobia, but as composite signs of nuanced discourses that target various aspects of Islam. There are, however, some peculiar characteristics of Twitter-and the Internet in general — that influence the ways these discourses are created and circulated.

\subsection{Specific Characteristics of Internet-Based Islamophobia}

Online Islamophobia is expressed through verbal violence that considers Islam as incompatible with the West, and dehumanizes Muslims by claiming that they should be removed from society. While these discourses have sadly been circulated long before the Internet, there are some ways social networks might further enhance their diffusion and modify the ways they are expressed. According to Brown (2018), online hate speech is characterized by anonymity, lack of physical presence, easy access, and instantaneousness. These characteristics largely apply to the dataset of post-Brexit tweets, which arguably rely on the anonymity of the platform and represent an immediate and impulsive reaction to the referendum. However, this does not only regard online Islamophobia, as Brexit resulted in a spike of anti-Muslim offline aggression as well (Tell Mama 2016b). The data analyzed in this article suggest that specific characteristics of online Islamophobia are rather linked to three other elements: the global connections allowed by the Internet, the proliferation of certain actors ("trolls" and "bots"), and the circulation of so-called "fake news."

The Internet helps people to connect with like-minded users and fosters global exchanges. Anti-Islam groups can reach national and trans-national audiences, as for example the German Islamophobic movement Pegida quickly diffused in other countries and gained international attention (Dostal 2015). This spread is arguably facilitated by the Internet, which helps the circulation of narratives in a relatively fast and cheap way. The global connections of Islamophobic ideas can be found in the dataset of post-Brexit tweets, where users often mention contexts other than the UK. While the referendum only involved British citizens, some consider Brexit as the victory of a certain type of political mentality diffused in many Western countries. The majority of the tweets, indeed, mention political personalities both from the UK—-such as the aforementioned Nigel Farage—and from outside the UK.

In particular, many connect Brexit with Donald Trump, who was at the time campaigning for the US presidential election. A tweet, for example, says "\#Brexit shows, thanks to Islam, Right is winning all over. Next up is America! Go Donald Trump!!" (24 June 2016). In this case, the tweet seems to consider Brexit-also framed as an anti-Islam vote-as part of a larger spread of a certain right-wing and racist mentality. This idea is expressed in many tweets quoting the hashtag \#MAGA (Make America Great Again, Donald Trump's slogan). Even if global connections of political and ideological movements existed also before the Internet, platforms such as Twitter undoubtedly help to spread and legitimize certain populist claims. People with similar ideas can get in contact with each other and share their opinions, and probably see themselves as part of an international political movement. In the aftermath of Brexit, Twitter helped Trump supporters in the US to reach a global audience by connecting their claims to those of UK voters, likely reinforcing also their Islamophobic views. The analysis of tweets suggests that Brexit gave some of these supporters the feeling they could freely express racist and Islamophobic views, and celebrate Donald Trump for publicly doing the same.

The type of interactions people experience on Twitter-short messages that can be circulated by many users-also favors the emergence of certain actors: the so-called "trolls" and "bots." Trolls are users that intervene in online debates with the aim of creating conflicts with inflammatory messages for the purpose of their own amusement (Maltby et al. 2016; Sanfilippo et al. 2018). Trolls often target an individual or a group to provoke a reaction or prove a point, such as the importance of free speech (Golf-Papez and Veer 2017). Bots are computer programming that mimic human behavior, but are 
actually generated by an algorithm (Jones 2015). Therefore, certain Twitter accounts might not be controlled by actual human beings, but generate automatic responses with the aim, for example, of increasing views on social networks or try to influence results in political elections. Bots had a relevant role in the debate preceding Brexit, especially in generating content in favor of the Leave position (Howard and Kollanyi 2016).

The presence of these actors on Twitter likely influences existing debates and contributes to the diffusion of hate speech. In the case of tweets sent in the aftermath of the British referendum, many users display trolling behaviors by sending a series of anti-Islam tweets. These tweets are often derogatory, and they seem to be written only to circulate abusive language that would upset other users. In observing the spread of Brexit-related discourses and creating my dataset, I came across many tweets that were likely produced by algorithms. For example, a tweet says "\#Brexit \#ISIS \#Islam \#Obama \#United States Good Show \#Brits !! \#Globalism \#HillaryClinton" (24 June 2016). It is sent from an account that displays neither a personal name, nor a picture or any information about the user. The fact that the tweet shows support for Brexit mainly repeating hashtags might be a symptom of a non-human actor, or of a trolling behavior. The presence of trolls and bots perpetuating Islamophobic narratives is a characteristic of social networks and risks decisively contributing to the visibility of anti-Islam discourses. These actors might be partially responsible for the high number of Islamophobic post-Brexit tweets, and their messages can influence the perception of Islam of all Twitter users that do not recognize them for trolls and bots.

Twitter-based messages are also characterized by the diffusion, operated by bots and humans alike, of the so-called "fake news." Currently an overused term by certain political characters, "fake news" in this article indicates news that is known to be false by their creators, and nonetheless circulated. According to Douglas (2018), fake news tends to be more prominent in the US and among right-wing people. They also have a connection with religion: fake news is often directed at Christians, in particular Protestant fundamentalists, and tend to mention religious content. For example, during the 2016 US presidential campaign, a high number of fake news reported an alleged involvement of candidate Hillary Clinton with ISIS and Islamic terrorism.

Many of the tweets sent after Brexit perpetrate fake news about Muslims. For example, a tweet says "Muslim imam says non Muslims $r$ worse than dogs and pigs including president of USA \#Brexit" (27 June 2016). The tweet contains a link to a Facebook page that appeared to be offline shortly after the publication of the tweet. There seem to be no reliable sources for the news, and it is likely that the Twitter user invented it, or that it comes from a Facebook page that spreads fake news. Nevertheless, it is quoted as a legitimate source. Similarly, many other tweets report news that comes from openly Islamophobic websites or conservative news outlets that do not provide proofs for the authenticity of the news. In this way, people seem to provide legitimation for their anti-Islam ideas, but they actually contribute circulating false stories with the only aim of perpetuating Islamophobia.

Global connections between right-wing individuals and movements, the proliferation of trolls and bots, and the creation and diffusion of fake news are only a part of social media interactions, and they do not condition all Internet debates. However, it appears that they played a role in post- Brexit Twitter exchanges, and they likely influence the creation of Internet-based Islamophobic discourses. Therefore, online Islamophobia can be conceptualized as a type of narrative connected to offline actions and discourses, but that has nonetheless some peculiar characteristics of diffusion and consumption.

\section{Discussing Online Islamophobia}

The analysis of Islamophobic tweets sent in the aftermath of the British referendum suggests that there are some dominant anti-Muslim themes: Islam is described as monolithic, violent, and unable to adapt to Western values. Many tweets are openly Islamophobic in dehumanizing Muslims and claiming they should be excluded from society because Islam is allegedly a manipulative political ideology rather than a sincere religion. These narratives often operate generalizations and conflate religion with race and ethnicity, praising Brexit as a solution against an alleged "invasion" of Muslim 
migrants and refugees. This perspective does not seem to distinguish between recent migrants, who do not necessarily belong to Islam, and European Muslims, who are not necessarily migrants. There are also references to gender, because Islam is described as opposed to women's rights. In this context, Islamophobic attacks do not specifically target Muslim women, who are often harassed in offline settings when they recognizably belong to Islam because of their veils; rather, anti-Islam tweets tend to advocate for the protection of Western women against Muslim men, described as unable to accept gender equality. These topics have characterized Islamophobic discourses for decades, as the Runnymede Trust already mentioned them in its report in 1997. The Internet arguably makes them more visible by enhancing their circulation.

Furthermore, Twitter helps to create global networks of like-minded people, offers spaces of interactions to trolls and bots, and contributes to the diffusion of fake news. The analysis of post-Brexit tweets suggests that they are not only Islamophobic, but often based on claims that are not verified, when not completely false. For example, they often praise politicians such as Donald Trump as allegedly being able to stop a "Muslim invasion," and blame other political actors for being part of a global "pro-Muslim conspiracy"; unverified accounts send a high number of tweets containing incorrect information; and many tweets embed fake news that comes from non-legitimate sources and has probably been created for Islamophobic purposes. Twitter is therefore likely to provide a space to spread factually mistaken information at the expense of Muslims, thus reinforcing Islamophobic discourses.

From this perspective, Islamophobic tweets have a "hypermediated" character. Hypermediation indicates the ways in which new technologies help people to intensify their networked relationships and allow for fast and emotional connections (Scolari 2015). These characteristics can be found in the analyzed dataset: while the content of the tweets can probably be found in other venues, Twitter contributes spreading it through concise, aggressive, immediate messages, sometimes embedding images or videos. If the Islamophobic narratives largely remain the same, Twitter offers a new framework to express it in different ways and rapidly spread them in multiple venues.

Tweets can be considered hypermediated also because they create networks between various media and non-media spaces (Evolvi 2018). Rapid exchanges and the spreading of false claims, indeed, are often facilitated by links and re-tweeting. Many tweets point to Facebook pages, anti-Islam websites, YouTube videos; sometimes they propose pictures that are likely taken from other Internet venues. They also often mention news media and events that happen offline. Arguably, there are connections between online and offline Islamophobic attacks occurred in the UK in the aftermath of Brexit. This means that Twitter helps the formation of networks between virtual and physical actions, mirroring and circulating discourses that exist in society and in various media venues.

Therefore, on the one hand, it is important to regulate the spread of hate speech on Twitter by punishing Islamophobic users as they would be punished when perpetuating anti-Muslim discourses offline. On the other hand, hate speech is not confined to a specific platform, and blocking users on Twitter alone might not stop them from using other venues. Arguably, it is important to take actions in regard to the general behavior of users: for example, it would be useful to spread digital media literacy in order to equip people with more tools to detect trolling behaviors and fake news, and to understand the detrimental implications of hate speech, in online as well as offline settings. While these are complex and long-term measures, the Internet can also provide spaces for Muslims to articulate their claims and have their voices heard, partially counteracting certain instances of Islamophobia.

\section{Conclusions}

This article explored the peculiar characteristics of online Islamophobia. In light of previous definitions and case studies, the analysis reveals that Internet-based Islamophobia enhances discourses that exist outside the Internet. Post-Brexit Islamophobic tweets can be considered hypermediated because they intensify existing discourses and put in connection different narrative spaces. Therefore, it is important to consider online Islamophobia as serious as offline anti-Muslim attacks: dismissing 
online Islamophobia as disconnected from society at large is not only inaccurate, but it risks normalizing the perpetuation of verbal anti-Muslim abuses also in physical venues. At the same time, there is a need to understand the peculiar characteristics of Internet-based Islamophobic discourses in order to better counteract their diffusion.

The hypermediated character of Internet exchanges, however, does not only necessarily promote hate speech and Islamophobia. The accessibility and affordability of platforms like Twitter, indeed, may help to amplify voices belonging to Muslims and other marginalized groups. Some Muslim women, for example created the hashtag \#MuslimWomenDay to share their personal experiences and fight Islamophobic prejudices on Twitter (Pennington 2018). When Dutch politician Geert Wilders created and circulated an anti-Islam video, some Muslims employed the Internet-and YouTube in particular-to respond to its Islamophobic allegations (Farida et al. 2011; Van Zoonen et al. 2011). These examples show that the possibilities offered by the Internet to create connections between different spaces can also have positive outcomes and serve the needs of marginalized groups, Muslims included.

This article focused on Islamophobic tweets written in relation to a specific event, Brexit. Venues for future research might include other examples of Islamophobia in different contexts and timeframes, in order to better understand its patterns. It would also be useful to consider online Islamophobia in relation to other types of hate speech, as they arguably have characteristics in common. Furthermore, future research might put in conversation online Islamophobic discourses with Muslims' responses to them. In this way, it would be possible to trace how the Internet can both enhance hate speech and constitute a space to counteract racism and social prejudices. This would help understand that the intrinsic characteristics of the Internet—such as the creation of hypermediated narratives-are not necessarily negative per se, but can produce negative outcomes depending on the intentions of the users. The possibilities offered by the Internet can also potentially result in actions that empower marginalized groups and counteract hate speech and Islamophobia, in both physical and digital spaces.

Funding: This research received no external funding.

Conflicts of Interest: The author declares no conflict of interest.

\section{References}

Allen, Chris. 2014. Britain First: The 'Frontline Resistance' to the Islamification of Britain. The Political Quarterly 85: 354-61. [CrossRef]

Allen, Chris. 2015. 'People Hate You Because of the Way You Dress': Understanding the Invisible Experiences of Veiled British Muslim Women Victims of Islamophobia. International Review of Victimology 21: $287-301$. [CrossRef]

Awan, Imran. 2014. Islamophobia and Twitter: A Typology of Online Hate against Muslims on Social Media. Policy E Internet 6: 133-50. [CrossRef]

Awan, Imran, and Irene Zempi. 2015. We Fear for Our Lives: Online and Offline Experiences of Anti-Muslim Hate Crime. London: Tell Mama, Available online: http:/ /irep.ntu.ac.uk/id/eprint/25975/ (accessed on 5 August 2018).

Bakali, Naved. 2016. Islamophobia: Understanding Anti-Muslim Racism through the Lived Experiences of Muslim Youth. Rotterdam: Sense Publishers.

Beydoun, Khaled A. 2018. American Islamophobia: Understanding the Roots and Rise of Fear, 1st ed.Oakland: University of California Press.

Brown, Alexander. 2018. What Is so Special about Online (as Compared to Offline) Hate Speech? Ethnicities 18: 297-326. [CrossRef]

Conover, Michael D., Bruno Gonçalves, Alessandro Flammini, and Filippo Menczer. 2012. Partisan Asymmetries in Online Political Activity. EPJ Data Science 1. [CrossRef]

Dostal, Jörg Michael. 2015. The Pegida Movement and German Political Culture: Is Right-Wing Populism Here to Stay? The Political Quarterly 86: 523-31. [CrossRef]

Douglas, Christopher. 2018. Religion and Fake News: Faith-Based Alternative Information Ecosystems in the US and Europe. The Review of Faith E International Affairs 16: 61-73. [CrossRef] 
Ekman, Mattias. 2015. Online Islamophobia and the Politics of Fear: Manufacturing the Green Scare. Ethnic and Racial Studies 38: 1986-2002. [CrossRef]

Elahi, Farah, and Omar Khan. 2017. Islamophobia: Still a Challenge for Us All. Runnymede Trust Publications and Resources. Available online: https:/ / www.runnymedetrust.org/uploads/Islamophobia\%20Report\% 202018\%20FINAL.pdf (accessed on 11 September 2018).

Esposito, John L., and Ibrahim Kalin, eds. 2011. Islamophobia: The Challenge of Pluralism in the 21st Century, 1st ed. Oxford and New York: Oxford University Press.

Evolvi, Giulia. 2017. \#Islamexit: Inter-Group Antagonism on Twitter. Information, Communication E Society, 1-16. [CrossRef]

Evolvi, Giulia. 2018. Blogging My Religion: Secular, Muslim, and Catholic Media Spaces in Europe, 1st ed.Abingdon: Routledge.

Farida, Vis, Liesbet van Zoonen, and Sabina Mihelj. 2011. Women Responding to the Anti-Islam Film 'Fitna': Voices and Acts of Citizenship on YouTube. Feminist Review 97: 110-29.

Gardner, Rod, Yasemin Karakaşoğlus, and Sigrid Luchtenberg. 2008. Islamophobia in the Media: A Response from Multicultural Education. Intercultural Education 19: 119-36. [CrossRef]

Garner, Steve, and Saher Selod. 2015. The Racialization of Muslims: Empirical Studies of Islamophobia. Critical Sociology 41: 9-19. [CrossRef]

Golf-Papez, Maja, and Ekant Veer. 2017. Don't Feed the Trolling: Rethinking How Online Trolling Is Being Defined and Combated. Journal of Marketing Management 33: 1336-54. [CrossRef]

Grosfoguel, Ramon. 2017. The Multiple Faces of Islamophobia. Islamophobia Research E Documentation Project (Blog), May 8. Available online: https:/ /irdproject.com/the-multiple-faces-of-islamophobia/(accessed on 1 October 2018).

Hopkins, Nick, and Vered Kahani-Hopkins. 2006. Minority Group Members' Theories of Intergroup Contact: A Case Study of British Muslims' Conceptualizations of Islamophobia and Social Change. British Journal of Social Psychology 45: 245-64. [CrossRef] [PubMed]

Howard, Philip N., and Bence Kollanyi. 2016. Bots, \#StrongerIn, and \#Brexit: Computational Propaganda during the UK-EU Referendum. arXiv, arXiv:1606.06356.

Hussain, Serena, and Jamil Sherif. 2014. Minority Religions in the Census: The Case of British Muslims. Religion 44: 414-33. [CrossRef]

Hussain, Yasmin, and Paul Bagguley. 2012. Securitized Citizens: Islamophobia, Racism and the 7/7 London Bombings. The Sociological Review 60: 715-34. [CrossRef]

Jackson, Daniel, Einar Thorsen, and Dominic Wring. 2016. EU Referendum Analysis 2016: Media, Voters and the Campaign. Early Reflections from Leading UK Academics. Available online: http://www. referendumanalysis.eu/ (accessed on 26 June 2018).

Jones, Steve. 2015. How I Learned to Stop Worrying and Love the Bots. Social Media + Society 1. [CrossRef]

Linehan, Thomas. 2012. Comparing Antisemitism, Islamophobia, and Asylophobia: The British Case. Studies in Ethnicity and Nationalism 12: 366-86. [CrossRef]

Magdy, Walid, Kareem Darwish, and Norah Abokhodair. 2015. Quantifying Public Response towards Islam on Twitter after Paris Attacks. arXiv, arXiv:1512.04570.

Maltby, John, Liz Day, Ruth M. Hatcher, Sarah Tazzyman, Heather D. Flowe, Emma J. Palmer, Caren A. Frosch, Michelle O'Reilly, Ceri Jones, Chloe Buckley, and et al. 2016. Implicit Theories of Online Trolling: Evidence That Attention-Seeking Conceptions Are Associated with Increased Psychological Resilience. British Journal of Psychology 107: 448-66. [CrossRef] [PubMed]

Meer, Nasar, and Tehseen Noorani. 2008. A Sociological Comparison of Anti-Semitism and Anti-Muslim Sentiment in Britain1. The Sociological Review 56: 195-219. [CrossRef]

Miller, Carl, Francesca Arcostanzo, Josh Smith, Alex Krasodomski-Jones, Susann Wiedlitzka, Rooham Jamali, and Jack Dale. 2016. From Brussels to Brexit/Islamophobia, Xenophobia, Racism and Reports of Hateful Incidents on Twitter. Channel 4 Dispatches-'Racist Britain.' Center for the Analysis of Social Media, Demos. Available online: https:/ / francescaarcostanzo.wordpress.com/publications / (accessed on 2 July 2018).

Mondon, Aurelien, and Aaron Winter. 2017. Articulations of Islamophobia: From the Extreme to the Mainstream? Ethnic and Racial Studies 40: 2151-79. [CrossRef]

Pennington, Rosemary. 2018. Making Space in Social Media: \#MuslimWomensDay in Twitter. Journal of Communication Inquiry 42: 199-217. [CrossRef] 
Philander, Kahlil, and YunYing Zhong. 2016. Twitter Sentiment Analysis: Capturing Sentiment from Integrated Resort Tweets. International Journal of Hospitality Management 55: 16-24. [CrossRef]

Poole, Elizabeth, and John E. Richardson. 2006. Muslims and the News Media. London: I.B.Tauris.

Runnymede Trust. 1997. Islamophobia: A Challenge for Us All. Runnymede Trust Publications and Resources. Available online: https:/ / www.runnymedetrust.org/companies/17/74/Islamophobia-A-Challenge-forUs-All.html (accessed on 21 June 2018).

Said, Edward W. 1979. Orientalism, 1st ed.New York: Vintage.

Sanfilippo, Madelyn R., Pnina Fichman, and Shengnan Yang. 2018. Multidimensionality of Online Trolling Behaviors. The Information Society 34: 27-39. [CrossRef]

Scolari, Carlos A. 2015. From (New)Media to (Hyper)Mediations. Recovering Jesús Martín-Barbero's Mediation Theory in the Age of Digital Communication and Cultural Convergence. Information, Communication $\mathcal{E}$ Society 18: 1092-107. [CrossRef]

Stewart, Heather, and Rowena Mason. 2016. Nigel Farage's anti-Migrant Poster Reported to Police. The Guardian, June 16. Available online: https://www.theguardian.com/politics/2016/jun/16/nigel-farage-defendsukip-breaking-point-poster-queue-of-migrants(accessed on 26 June 2018).

Tell Mama. 2016a. A Constructed Threat: Identity, Prejudice, and the Impact of Anti-Muslim Hatred. Tell Mama Annual Report, London. Available online: https://tellmamauk.org/wp-content/uploads/2017/11/AConstructed-Threat-Identity-Intolerance-and-the-Impact-of-Anti-Muslim-Hatred-Web.pdf (accessed on 2 September 2018).

Tell Mama. 2016b. The Brexit Result Had a Lasting Impact on Race and Religious Hate Crimes. Available online: https: / / tellmamauk.org/the-brexit-result-had-a-lasting-impact-on-race-andreligious-hate-crimes / (accessed on 2 September 2018).

Wilkinson, David, and Mike Thelwall. 2012. Trending Twitter Topics in English: An International Comparison. Journal of the American Society for Information Science and Technology 63: 1631-46. [CrossRef]

Wood, C., and Mick Finlay. 2008. British National Party Representations of Muslims in the Month after the London Bombings: Homogeneity, Threat, and the Conspiracy Tradition. British Journal of Social Psychology 47: 707-26. [CrossRef] [PubMed]

Würschinger, Quirin, Mohammad Fazleh Elahi, Desislava Zhekova, and Hans-Jörg Schmid. 2016. Using the Web and Social Media as Corpora for Monitoring the Spread of Neologisms. The Case of 'Rapefugee', 'Rapeugee', and 'Rapugee'. Paper presented at 10th Web as Corpus Workshop, Berlin, Germany, August 12; pp. $35-43$. [CrossRef]

Zempi, Irene, and Imran Awan. 2016. Islamophobia: Lived Experiences of Online and Offline Victimisation. Bristol: Policy Press.

Van Zoonen, Liesbet, Farida Vis, and Sabina Mihelj. 2011. YouTube Interactions between Agonism, Antagonism and Dialogue: Video Responses to the Anti-Islam Film Fitna. New Media E Society 13: 1283-300. [CrossRef] 